\title{
Antonio Candido, sempre agora
}

\author{
MARIA THEREZAFRAGAROCCO
}

Maria Antonia, 1963, Curso de Letras.

Impossivel não recuar no tempo e não tentar a recuperação de algumas sensaçōes e experiências vividas em um curso ministrado por Antonio Candido.

Muito já se disse da atração exercida por suas aulas "inenarráveis" como bem as chamou Walnice N. Galvão (1).

No entanto, mesmo que difícil traduzi-las com a fidelidade exigida, a tentação de revivê-las se impõe de forma inarredável, sobretudo quando se tem em mãos um livro como o recém-lançado $O$ Estudo Analítico do Poema e que traz à luz, de modo muito vivo, duas das facetas fundamentais que compōem a figura de Antonio Candido: a do grande intelectual, de cultura ampla, dono de sensibilidade refinada que o transformou no " maior crítico literário em atividade no Brasil"; e aquela outra, que se ajusta tão bem à primeira, completando-a magistralmente, qual seja: a do excelente professor universitário que, conforme diz Davi Arrigucci Jr., sempre conseguia, em sala de aula, "com notável senso de auditório, comunicar até o mais complexo e intratável dos assuntos em termos acessíveis à maioria", tornando-se em classe um "mestre incomparável" (2).

Neste livro de que ora falamos, Antonio Candido "permite" que venha a público parte do programa de um curso por ele ministrado aos alunos do $4^{8}$ ano de Letras, em 1963 e 1964, e cujo objetivo, ao propor, foi o de ensinar literatura "de maneira aderente ao texto, evitando teorizar demais e procurando a cada instante mostrar de que maneira os conceitos lucram em ser apresentados como instrumentos de prática imediata, isto é, de análise" (3).

Em Nota Inicial, de 1987, o autor faz um pouco a história do curso e das proprias aulas-datilografadas, uma por uma - em mais ou menos quatro páginas, para que a partir daí fosse desenvolvida sua exposição em classe. Acrescenta também que "as notas do livro registram um momento no ensino de literatura de nossa faculdade", razão pela qual afirma ter concordado em que fossem impressas " como documento daquele início dos anos de 1960" (4).

Sem dúvida essas "notas" constituem-se em importante fonte documental do que foi o ensino de literatura na Faculdade de Filosofia, há três décadas. Mas são mais, muito mais que documento. A forma pela qual o curso é apresentado já denota a natureza da sensibilidade crítica de Antonio Candido e que perpassa todos os trabalhos do autor.

E também aqui, na medida em que revela o tratamento crítico-dialético com que aborda as tendências que marcaram a história dos estudos de literatura, Antonio Candido já dá indicações sobre boa parte do caminho seguido por sua investigação teórica, cuja intenção era de desenvolver um método crítico que, ainda no dizer de Arrigucci, " fosse de fato estético e histórico a um só tempo, recusando sua redução a meras técnicas de descrição formalista e procurando ver o social em sua pertinência com relação ao estético" (5).

Desse modo, o programa de curso contido no livro, ainda que não se desenvolva mais amplamente como texto crítico, traz já essas características anunciadas.

Compõe-se o livro fundamentalmente das duas partes iniciais do programa, sendo que os outros dois tópicos finais, relativos à integraçāo da linguagem poética às estruturas significativas iam sendo desenvolvidos "à medida que se realizavam as análises dos poemas", conforme conta o próprio autor.
MARIA THEREZA FRAGA ROCCO É professora associada da

Faculdade de Educaçäo da USP.

Antonio Candido, O Estudo Analtico do Poema - Terceira Leitura, Sảo Paulo, FFLCH.USP.

\footnotetext{
1 Walnice N. Galvảo, "Aula de Antonio Candido". in Antonio Candido. O Estudo Analitico do Poema - Terceira Loitura, Sáo Paulo. FFLCH.USP, $n^{\circ} 2, \mathrm{~s} / \mathrm{d}, 2^{\circ}$ e $3^{\circ}$ capas.

2 Davi Arrigucci Jr., " Movimento de um Leitor. Ensaio e Imaginação Critica em Antonio Candido", in Folha de S. Paulo, 23/11/1991, Caderno 6. p. 3.

3 Antonio Candido, O Estudo Analltico do Poema, op. cit. p. 6.

4 Idem, ibidem.

5 Davi Arrigucci Jr., op. cit., p. 5.
} 
O texto, pois, em sua primeira parte trata dos Fundamentos do Poema: sonoridade, ritmo, metro e verso. $\mathrm{Na}$ segunda parte, desenvolve-se o estudo das chamadas Unidades Expressivas, momento em que Antonio Candido discorre sobre "Os Destinos das Palavras no Poema", realizando uma análise das "modalidades de linguagem figurada" e detendo-se sobre "A Natureza da Metáfora", ocasião em que nos presenteia com um texto de extrema atualidade.

Partindo da Retórica Tradicional, passando pela teoria de Vico e chegando a Bachelard, com a idéia do devaneio - visto como atividade essencial ao homem, Antonio Candido produz uma das mais competentes peças teóricas sobre a metáfora e que vem toda ilustrada por exemplos belíssimos, reveladores da sensibilidade que presidiu a escolha. Voltaremos à questão mais adiante.

Não pretendo analisar cada um dos tópicos contidos nos Fundamentos ou nas Unidades Expressivas do poema. Tratarei mais longamente de alguns itens, passando um tanto quanto em "vol d'oiseàu" sobre os outros.

O que irá determinar a escolha deste ou daquele tópico será um pouco aquilo que mais fortemente marcou a lembrança de quem, há quase três décadas, fez o curso de Antonio Candido, em 1963.

Ao desenvolver o problema da sonoridade no poema - de sua natureza e suas leis -, Antonio Candido iniciava a exposição, explorando a teoria de M. Grammont, abordagem que reduz sensivelmente, como afirma, no curso posterior de 1964 .

Como não é e nunca foi proprio do autor embarcar em modismos, Antonio Candido não endossa inteiramente a teoria do foneticista francês e, já àquela época, chamava a atenção dos alunos, advertindo-os de que o problema, de modo algum, encontrava-se satisfatoriamente resolvido.

Assim é que, ao tratar da questão relativa às fixas correspondências preconizadas entre som e sentido e ainda da expressividade rígida deste ou daquele som, Antonio Candido mostrava aquela sutil verve irônica que sempre o caracterizou tão bem. Ao se referir, por exemplo, a algumas " escolas" literárias, critica com muito humor os excessos de alguns poetas em determinados momentos.

Discorrendo sobre recursos sonoros, como certas homofonias obtidas através de rimas, assonâncias, aliteraçōes, o autor desloca-se para o Simbolismo e, com essa ironia que lhe é muito própria, analisa a primeira estrofe de Pesadelo de Eugenio de Castro:

\footnotetext{
" Na messe que enloirece estremesse a quermesse, O sol, o celestial girassol, esmorece, $\mathrm{E}$ as cantilenas de serenos sons amenos Fogem fluidas, fluindo à fina flor dos fenos" ,
}

6 Antonio Candido, O Estudo Analftico do Poema, p. 28.

7 Idem, ibidem, p. 30.

8 Idem, ibidem, p. 46.

9 Idem, ibidem, p. 60. observando que "os simbolistas se abandonaram a uma verdadeira orgia métrica e sonora", sendo que nessa primeira estrofe o poeta lança mão de "rima interna obsessiva, assonâncias, aliterações, etc., acumuladas de modo quase delirante" (6).

Ainda sobre a questão da sonoridade, e mesmo reproduzindo exemplos reforçadores da teoria de Grammont, Antonio Candido nota que tais efeitos sonoros são " conscientemente procurados e obtidos pela intensificação dos recursos utilizados" - fato que contribui para "forçar" o valor expressivo do som.

Em um lúcido contraponto à teoria de Grammont, adverte o autor que "quando se fala em estrutura sonora, fala-se da sonoridade de qualquer poema, pois todo poema tem a sua individualidade sonora própria", sendo que "o efeito expressivo, mesmo de caráter sensorial, pode ser obtido por outros recursos e principalmente pelo valor semântico das palavras escolbidas" (grifo meu), acrescentando finalmente que, " em oposição à tese da expressividade objetiva do som", tem-se que tal efeito, na poesia, depende de outros aspectos, "sobretudo do próprio sentido das palavras que são o elemento diretor" (7).

Antonio Candido conclui suas reflexōes relativas à sonoridade, apoiando-se naquele jogo feliz de revisão e análise de conceitos que se opõem, e que não podem ser tomados como definitivos e definidores de uma situação.

Assim como ocorreu no tratamento da sonoridade, todo o texto do autor vai se construindo sobre a bipolaridade existente na convivência de afirmações contraditórias e sobre a posterior discussão dessas afirmaçōes às quais fornece argumentos e contra-argumentos - mantendo, desse modo, muito viva aquela tensão necessária também aos textos didático e crítico. 
Quanto aos outros aspectos que fundam o poema, no tocante à rima por exemplo, Antonio Candido vai histórica e criticamente caracterizando os modos de rima que predominaram nos diferentes períodos literários.

Passa em revista, então, as várias formas de homofonias, detendo-se nas preferências sonoras dos parnasianos, dos simbolistas e dos modernistas. Falando da evidente tendência de dessonorização do verso, observada em vários movimentos literários, Antonio Candido chama a atenção para a existência, naquele momento, de uma retomada intencional da sonorizaçäo, que vinha ocorrendo mesmo entre aquelas práticas poéticas que, na época, em pleno apogeu, privilegiavam "o efeito visual ao lado do efeito sonoro" , já que seus autores pensavam em fazer uma poesia para os "olhos da civilização" do tempo.

E com observação que preserva um sabor extremo de atualidade, Antonio Candido comenta que, entre os que procuravam ressaltar o visual em detrimento do sonoro, contra esses criadores parece ter ocorrido uma "curiosa vingança da sonoridade poética", pois "os poetas que valorizam o efeito visual, como os concretistas, são os que também mais dependem do efeito sonoro" (8).

Analisando a seguir cada um dos demais elementos fundadores do poema, Antonio Candido se reporta a ritmo, metro e ao próprio verso, sempre nessa linha de abordagem teórica construída a partir de teses e antíteses - em função do que discute tensamente os conceitos, mas com a sobriedade e o equilíbrio próprios de quem intui e domina as contradiçōes evidentes em tais conceitos, bem como nos textos que os contêm.

Semelhantemente ao que fizera com respeito à sonoridade, às homofonias de modo geral, Antonio Candido trata amplamente do ritmo, fala das diferentes formas, das diferentes concepçōes que, em momentos diversos, procuraram dar conta do conceito.

Após analisar os procedimentos das várias estéticas e apontar os entraves que impedem uma aceitação total deste ou daquele tipo de tratamento teórico, o autor observa, com extrema contemporaneidade para nós hoje, que, considerando o ritmo enquanto "alma do verso", ele deve ser entendido como algo mais do que um simples capricho dos poetas, configurando-se antes enquanto manifestaçấo da "sensibilidade do homem nas suas variaçōes através do tempo" (9); como algo visceral em relaçāo à sensibilidade humana e não como um "mero recurso técnico".

Ao tratar do verso, Antonio Candido nos mostra com aguda percepção que o verso, em verdade, não se sustenta pelos fonemas, pelas sílabas, ou por meio dos segmentos rítmicos que dele também fazem parte. $O$ verso, antes de mais nada, calca-se na palavra - na polissemia da palavra - que é a sua unidade fundadora; na palavra que, em poesia, realiza-se sob forma de imagens inesperadas, de sonoridade imprevisível; nessa palavra que se mostra impregnada de sentidos plurais, que muitas vezes se revelam contraditórios, reforçando assim aquela idéia da presença de tensăo que se erige como elemento original e necessário à estruturação de textos.

Chegando ao estudo das Unidades Expressivas e Rítmicas do poema, $\mathrm{c}$ autor destaca aquelas que considera constitutivas essenciais da linguagem poética.

(Realiza, então) a

bela reflexão sobre

a metáfora... Recorrendo

a Vico, e mesmo

discordando de algumas

de suas proposiçōes,

Antonio Candido nos

mostra que a metáfora,

"longe de ser uma

forma historicamente

superável do

pensamento humano",

configura-se antes

"como um processo

criador que manifesta

de forma sui generis

a atividade

mental do

homem" 
Nesse momento, Antonio Candido projeta para o leitor, com absoluto timbre de atualidade, a figura de Vico e de sua Scienza Nuova. Concordando em vários pontos com o teórico italiano, observa que, contrariamente ao pensamento da Antiga Retórica, as imagens não são "enfeites" do discurso, mas sim "elementos viscerais da expressão". Considera ainda que a teoria de Vico, "ousada e brilhantíssima", é sem dúvida precursora da modernidade, ainda que tenha ficado "mais de um século no esquecimento" .

Na seqüência, nosso autor desenvolve um denso e ao mesmo tempo sintético estudo sobre a linguagem figurada dos poemas: um estudo crítico e histórico que, partindo dos preceitos da já referida Antiga Retórica, detém-se nas tendências logicistas do século XIX, chegando até o ponto de atingir as variáveis teóricas com que o século XX vem marcando a questão.

Concordando ainda com Vico, Antonio Candido ensina que devemos nos fixar sobre quatro tropos essenciais: metáfora metonímia sinédoque e tronta sem nos esquecermos da imagem e do símbolo.

Nesse momento é que realiza a bela reflexão sobre a metáfora já referida. Recorrendo a Vico, e mesmo discordando de algumas de suas proposições, Antonio Candido nos mostra que a metáfora, "longe de ser uma forma historicamente superável do pensamento humano", configura-se antes "como um processo criador que manifesta de modo sui generis a atividade mental do homem" (10).

Encerrando a discussão sobre metáfora, Antonio Candido indica já ser possível integrar tal estudo ao problema mais amplo da linguagem poética, visto que a questão da metáfora é tão abrangente que lança luz sobre todas as angulações desse tipo de linguagem figurada.

E como se dá a passagem de tais reflexões teóricas do autor face à realidade concreta do poema, quando visto em sala de aula?

É preciso registrar fortemente um ponto nuclear. As aulas de Antonio Candido, durante o curso todo, e mesmo em outros seguidos posteriormente, mantinham um ritmo contínuo que ia da teoria para o texto e do texto vinha para novas teorizações.

Mesmo aqueles ainda näo-iniciados, e que estavam sendo introduzidos em sua arte, já sentiam bem nítida a presença desse movimento oscilatório ininterrupto.

$\mathrm{E}$ assim ocorreu também com o grupo que estreava no trabalho de "teoria literária" , naquele ano de 1963, na rua Maria Antonia. Já conhecendo Antonio Candido por figura e nome, alguns de nós do $4^{9}$ ano de Letras - e que no ano anterior espiávamos as pessoas importantes que assistiam o curso do mestre, como Lygia Fagundes Telles, Lupe Cotrim Garaude - nos defrontamos entâo com a primeira aula do curso de poema.

Sério, sóbrio, afável e exigente a um só tempo, o professor Antonio Candido começava suas aulas - como aliás ocorre também neste livro de que tratamos entremeando já todas as observaçōes por um sem-número de exemplos poéticos atraentes e até mesmo perturbadores.

Aprendemos que o nome do que antes dizíamos ser poesia - era poema. Aprendemos também que um primeiro e básico mandamento para o trabalho com literatura consistia em ler o texto escolhido, em ler muito o texto-poema escolhido, como aliás repete, em 1984, o próprio Antonio Candido, no prefácio do seu Na Sala de Aula: "ler infatigavelmente o texto analisado é regra de ouro do analista... A multiplicaçāo das leituras suscita intuições que são o combustível neste ofício" (11).

Tínhamos, portanto, que ler poemas. Ler aquele poema escolhido. Ler várias vezes. Ler tanto até quase sabê-lo de cor. Ler de forma que, se estivéssemos na rua, no ônibus, não importa onde, pudéssemos ligar tal texto a alguma coisa especial que víssemos, percebêssemos, intuíssemos - pois mesmo sem o texto em mãos, ele tinha que estar inteiro, intacto em nossas cabeças. Como, de resto, permanece até hoje.

Foi-nos indicada a Antología Poética de Manuel Bandeira, da Editora do Autor (12). Antonio Candido nos orientou para que lêssemos todos os poemas e anotássemos o nome daqueles que mais nos tinham atraído. Era tarefa para a aula seguinte. Não se tratava exatamente de uma ordem - antes uma indicação de caminho que pessoa alguma sequer cogitava em não seguir.

"Peregrinação" : o poema que mais me tocou. Fomos à página 132 da antologia. Começamos a leitura... Mas não era essa a "Peregrinação" que eu havia escolhido. Encantei-me foi com um soneto do mesmo nome e que estava na "Estrela da Tarde" e não em "Lira dos Cinqüent'Anos" :

Manuel Bandeira, Antologia Postca, Rio de Janeiro, Editora do Autor, 1962. 
" Quando olhada de face, era um abril:

Quando olhada de lado, era um agosto.

Duas mulheres numa: tinha o rosto

Gordo de frente, magro de perfil.

Amor total e falho... Puro e impuro...

Amor de velho adolescente... e tão

Sabendo à cinza e pêssego maduro..." (13)

Antonio Candido, como fazia com todos os textos que cada um de nós indicava, leu o poema todo, disse o poema, daquela forma tão especial que caracterizava suas leituras em classe. Reconheceu que minha escolha tinha razão de ser, que o poema era mesmo muito bom. E já nessa segunda ou terceira aula nos introduziu aos processos de comentário e análise de que trata o livro que ora discutimos.

A primeira estrofe de "Peregrinação", segundo ele, lembrava as mulheres da fase azul de Picasso. Já o último terceto nos lançava em cheio ao problema da tensão causada pela convivência das contradições. De pronto, de chofre e para sempre, entendemos que, da tensão, da integração de contradições, origina-se a matriz primordial dos poemas.

Cada aluno falando sobre os textos de que mais gostara; Antonio Candido comentando, lendo e fazendo observações - ao final desse dia, tínhamos praticamente percorrido a antologia toda para eleger um poema específico de estudo.

Alguns queriam que fosse "Vou-me embora pra Pasárgada" - tão bonito e tão famoso! Eu continuava com minha "Peregrinação". Sábia e pertinentemente, Antonio Candido nos fez mudar de rumo: "Pasárgada", sim, é um poema muito bonito - mas também, dos mais analisados e conhecidos. Assim, sem que bem nos déssemos conta, acabávamos por chegar à opção definitiva e, evidente, a um trabalho de comentário, de análise e até a alguns níveis de interpretação - pois, apesar de o curso, teoricamente, como se percebe no livro, se deter mais sobre comentário e análise, a interpretação nunca esteve ausente.

A escolha recaiu em "Última Canção do Beco" (14). Semanas e semanas permanecemos debruçados sobre o poema. Não só reconstruímos mentalmente o Beco - e não por elipses - como também percorremos o "Itinerário de Pasárgada" (15), em que Manuel Bandeira descreve - criando oportunidade para se discutir a problemática da inspiração - a forma pela qual o poema se construiu ou foi construído.

Já sabendo de cor o texto todo, enxergando materialmente nos versos o lugar das oposições, os pontos de tensão; já analisadas a sonoridade, as recorrências, a natureza das alternâncias vocálicas, e mesmo desbastando Grammont, observávamos também os tipos de rima e o ritmo que presidia o texto. E chegávamos ainda d̀ metáforas que iam sendo encontradas, analisadas e interpretadas.

"Vão demolir esta casa.

Mas meu quarto vai ficar

Não como forma imperfeita

Neste mundo de aparências:

Vai ficar na eternidade,

Com seus livros, com seus quadros,

Intacto, suspenso no ar!" (16)

A imagem projetada introduzia no poema o elemento infinito e eterno no recorrente tema de quarto em Manuel Bandeira. S6 o quarto, com seus objetos, tem valor para o poeta - traduzindo uma existência essencial num mundo imperfeito porque de aparências.

Beco: santo e cheio de pecados; Beco: rua de mulheres e também de carmelitas; Beco, Lapa: do pecado e das graças angelicais. O Beco, sim, entendemos então, era a própria vida que traz em seu bojo a convivência equilibrada de tantos opostos.

Estávamos já interpretando...

O curso exigia um trabalho final, uma monografia - seria a análise de um outro poema. Novamente o processo de escolha. Agora mais fácil porque conhecíamos e bem praticamente todos os textos da antologia.

Antonio Candido, com aquele poder todo especial de persuadir sem parecer, nos

13 Idem, ibidem, p. 180.

14 Idem, ibidem, p. 125.

15 Idem, " ltinerário de Pasárgada". in Poesia Completa e Prosa, Rio de Janeiro, Aguilar Ed., 1974.

16 Idem, " Última Canção do Beco", in Antologia Poética, op. cit., pp. 125. 
fez andar por outro caminho. Năo mais um poema comportado, na mesma linha de " Última Canção do Beco". A proposta foi de que trabalhássemos com a "Balada das Três Mulheres do Sabonete Araxá" (17) - poema que, no dizer do próprio Bandeira, deve ter parecido "bem cafajeste à geração de 45 ", pois quebrava muito do "decoro verbal" tão presente em boa parte de seus outros textos.

Estranhamos um pouco no começo. Estava difícil entender. Quanto mais escrever sobre "As Três Mulheres..." . Antonio Candido então propôs que lêssemos e começássemos a trabalhar juntos em classe.

Era natural o estranhamento; afinal o poema detinha "um ritmo discursivo irônico" pouco comum; era uma piada tendendo para a paródia.

Houve gente que desenterrou, não sei de que baú, páginas de revistas antigas, contendo a figura do "anúncio" do sabonete Araxá com suas três feias e desbotadas mulheres.

Era tempo de comentário - apareciam a paródia, a piada e as referências a outras obras literárias: "O meu reino pelas três mulheres do Sabonete Araxá" remetia-nos a Ricardo III. E íamos lá, alguns de nós, ao texto de Shakespeare, tentando achar o porquê dessa ocorrência poética. Antonio Candido então nos explicava que era usual os poetas lançarem mão, em seus textos, do trabalho de outros poetas: parodiando-os por graça, ou então levando-os muito a sério.

Nessa hora, o professor nos apresentou a T. S. Eliot e a "The Waste Land". De quantas obras, de quantos outros poetas, T. S. Eliot emprestou alguns versos, refazendo-os ou intercalando-os entre os seus próprios.

Vimos então que na "Balada das Três Mulheres do Sabonete Araxá", da mesma forma que se recorria a Shakespeare, emprestavam-se também trechos de conhecida canção popular: "... mulatas cor da lua vem saindo cor de prata" . E o que pretenderia o poeta com tudo isso? Por certo, brincar com o próprio devaneio e, como num sonho, enumerar sem lógica aparente as prioridades sem importancia da própria existência:

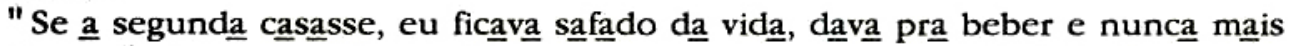
telefonava" . A enumeração contida no verso aponta para uma atribuição decrescente dos valores dessas açōes tão banais. Mas, voltando um pouco o pensamento a Grammont, o que mais encafifava mesmo eram todos aqueles a que apareciam qual seria o significado deles? O que revelavam? O que escondiam? A resposta, que naquele tempo não veio, ficou esquecida hoje, como também a preocupação.

Eram já momentos de comentário, análise e interpretação, e que claramente marcavam o início de nossa "penetração simpática" no universo dos poemas.

Disse Antonio Candido neste livro que: " em aula a matéria ia sendo não apenas desenvolvida, mas completada por elementos que nela não aparecem" (18). Se nem todos os elementos do processo se fazem presentes no livro, encontram-se, porém, subjacentes nos exemplos transcritos e, sem dúvida, permanecem gravados com mais fortes contornos ou entåo mais esfumados em todos os que seguiram este e outros cursos de Antonio Candido.

Fala hoje o professor que "em todo o caso, feitas as ressalvas", é possível que "o texto deste livro, meio desconjuntado, ainda interesse aos meus alunos aos quais se destina, como lembrança de nosso trabalho comum" (19).

Sim, interessa muito aos que foram alunos de Antonio Candido. Mas não só a eles. Interessa a todos pela atualidade e profundidade das reflexōes aí contidas. Interessa a todos que tenham uma ligação de amor com a poesia, com a literatura.

E mais: o texto não é " desconjuntado", não. É texto inteiro - estruturado por uma linha de pensamento crítico que vem à luz com muito brilhantismo, equilíbrio e com grande noção de medida. É texto integro - preparado por um scholar, por um professor universitário que sempre demonstrou enorme respeito pelos alunos com que trabalhava; professor que, sem nunca baratear ou diluir o conhecimento, conseguia levar seus auditórios a um visível crescimento intelectual, a um apuro daquele tipo de sensibilidade crítica que todo universitário precisa desenvolver, em maior ou menor grau.

Por tudo isso, penso que $O$ Estudo Analítico do Poema, além de completar o já clássico Na Sala de Aula integra-se obrigatoriamente à bibliografia fundamental e necessária ao aluno e ao professor de universidade que goste de poesia, que trabalhe sobre o poético, que trate, enfim, do literário.

18 Antonio Candido, O Estudo Analltico do Poema, p. 9.

19 Idem, ibidem, p. 10. 